\title{
History of Power Transmission Technologies and Future Prospects of Power System of Chubu Electric Power Company
}

\author{
Hirotaka Takagi Member (Chubu Electric Power Co. Inc.) \\ Tomonari Sugiyama Member (Chubu Electric Power Co. Inc) \\ Toshihito Zashibo Member (Chubu Electric Power Co. Inc)
}

Keywords : power system, capacity scale-up, compactification, power system stabilization, system coordination, electricity market liberalization

Since its foundation (1951), CEPCO's power system has developed through efficient power source and transmission facility formation to meet electricity demand increases. During this period, various situations have significantly changed, which have required capacity scale-up, compactification, landscape conservation, etc. of power systems. The progress of transmission technologies that CEPCO has adopted shall be described hereafter.

It is said that single copper wire was adopted for the first transmission line in Japan. Later on, hard drawn copper (HDC) strand wire, aluminum conductor steel reinforced (ACSR) strand wire was successively adopted for corresponding to larger transmission capacity due to the electricity demand increase. Meanwhile, configuration of transmission line wire has been shifted to larger number of conductors.

Extra-large bundle radius six-conductor system, with an extended conductor spacing $(120 \mathrm{~cm})$, was adopted for $500 \mathrm{kV}$ Etsumi trunk line in 1998, for transmission capacity scale-up and lower inductance. $410 \mathrm{~mm}^{2}$ thermo-resistant Aluminum Conductor Steel Reinforced (TACSR) that was improved in heatresistanceand capacity was adopted for it.

Underground cable that CEPCO's predecessor company adopted for was paper insulated lead sheathed and steel tape armored (PTA) cable. Later on, separately lead sheathed (SL) cable, oil filled (OF) cable, was successively adopted for corresponding to larger transmission capacity due to the electricity demand increase. Currently most used is cross-linked polyethylene insulated vinyl sheathed $(\mathrm{CV})$ cable, that is adopted for from distribution line cables to $275 \mathrm{kV}$ underground cables.

In addition, CEPCO constructed gas insulated transmission line (GIL) that was equal to overhead transmission line in capacity. This GIL is $3.3 \mathrm{~km}$ in line length, the world longest.

Meanwhile, difficulties in land acquisition required not only transmission line capacity scale-up but also its compactification. Therefore, CEPCO has reduced the site area through adopting new

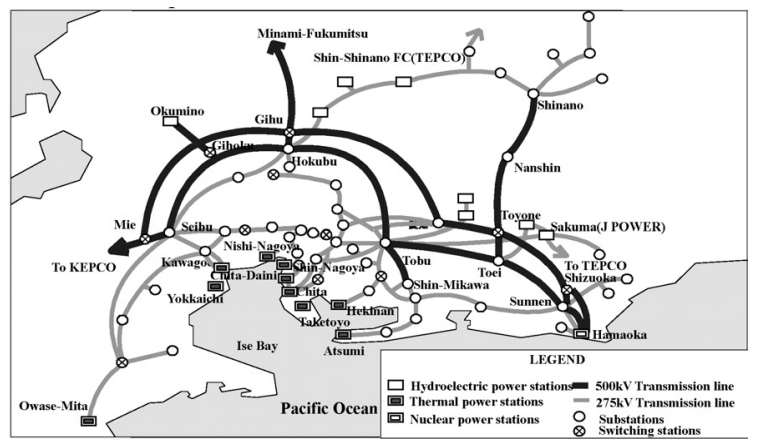

Fig. 1. Power system of CEPCO in 2006

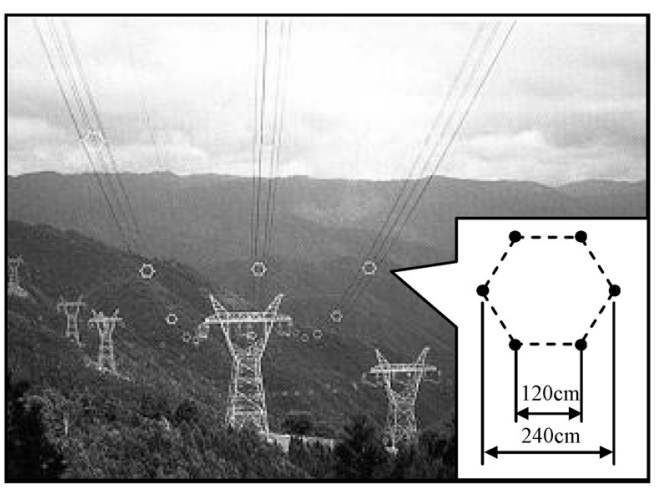

Fig. 2. Extra-large bundle radius six-conductor system of Etsumi trunk line

bus configuration and gas insulated switchgear (GIS).

CEPCO accommodated the whole $500 \mathrm{kV}$ and $275 \mathrm{kV}$ switchgear at Shin-Mikawa substation that commenced operation in 1983, into GIS. Adoption of three-phase packaged main-bus type for $500 \mathrm{kV}$ GIS, the first in the world for this voltage class, reduced site area further than the conventional phase-separation type GIS. These compactification technologies collectively reduced the site area of Shin-Mikawa substation to one third of an open-air substation of the same class.

The power system of CEPCO has developed since its foundation, which required further stabilization and upgrading of operation of the trunk line power system, advancing power system stabilization tehnologies.

CEPCO was adopted system stabilizing controller (SSC) and transient stability controller (TSC) that cut off required loads or power sources in order to contain fault spread due to power system turbulence. Among these systems, online TSC, which recognizes present state of power system configurations, that CEPCO developed and put it on commercial operation for the first time in the world.

The progress of power transmission technologies was above described. The transmission capacity scale-up and lower inductance that the progress brought are creating new problems including increases in short circuit and ground fault currents, which requires multilateral and cross-sectoral solutions (system coordination). Furthermore, two major changes in business environment, which are electricity market liberalization and rising public awareness of environment and right consciousness, may bring new challenges on power system planning. Sufficient consideration and evaluation on effects that changes in business situation bring are required for optimum power system planning from a multilateral perspective on the entire power system. 


\title{
History of Power Transmission Technologies and Future Prospects of Power System of Chubu Electric Power Company
}

\author{
Hirotaka Takagi* $\quad$ Member \\ Tomonari Sugiyama** Member \\ Toshihito Zashibo** Member
}

\begin{abstract}
Since its foundation, the power system of Chubu Electric Power Company (hereinafter CEPCO) has developed through power source and transmission facility formation to meet electricity demand increases. This development has been accompanied by progress in transmission technologies including capacity scale-up, compactification and power system stabilization to operate complex power systems. Now, changes in business situation due to electricity market liberalizatin may bring new challenges to future facility formation. This paper reviews CEPCO's history of power system formation and progress in transmission technologies, and describes future challenges.
\end{abstract}

Keywords : power system, capacity scale-up, compactification, power system stabilization, system coordination, electricity market liberalization

\section{Introduction}

Since its foundation (1951), CEPCO's power system has developed through efficient power source and transmission facility formation to meet electricity demand increases. During this period, social, economical and environmental situations have significantly changed, which have required capacity scale-up, compactification, landscape conservation, etc. of power systems. Corresponding to these changes, transmission technologies have progressed in many aspects, based on which power systems have formed efficiently.

However, differing from traditional power systems, where power generation and transmission are integrated, future power system formation may face new challenges due to electricity market liberalization and enhanced environmental awareness.

Against this background, this paper reviews CEPCO's history of electric power system formation and progress in major transmission technologies. And authors give our future views on further progress of technologies required, ideal methods of system coordination, and measures devised to deal with environment.

\section{Power System Formation in the Past}

2.1 Transition of Electricity Demand ${ }^{(1)} \quad$ Since its foundation in 1951, the electricity demand to CEPCO has steadily increased. Corresponding to this demand increase, CEPCO has developed its power system through efficient power source and transmission facility formation to secure stable electricity supply.

\subsection{Power System at CEPCO's Foundation (1951) ${ }^{(1)}$}

Figure 1 shows the outline of power system at CEPCO's foundation (1951). Hydropower was the main power source then, and rapidly increasing electricity demand had continuously outpaced supply capacity. CEPCO made full efforts to develop power sources, which finally balanced the electricity demand and

* Electrical Engineering Department, Power System Division, Chubu Electric Power Co, Inc.

1, Higashi-shincho, Higashi-ku, Nagoya 461-8680

** Planning Section, Electrical Engineering department, Power System Division, Chubu Electric Power Co, Inc.

1, Higashi-shincho, Higashi-ku, Nagoya 461-8680

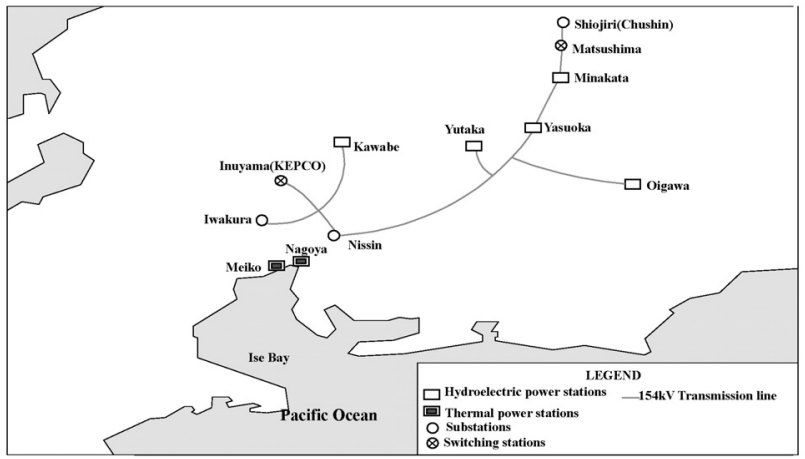

Fig. 1. Power system diagram in 1951

supply in 1955. Meanwhile, the transmission facilities were unstable with their framework of two $154 \mathrm{kV}$ systems where a local fault may spread over the whole power system. Thus, CEPCO constructed a dedicated trunk line for each river system and other linking lines to the $154 \mathrm{kV}$ system.

2.3 Power System Development up to $1971^{(1)}$ The rapid economic growth during this period increased electricity demand by an annual average of $12 \%$.

Since feasible hydropower source sites had been exhausted, CEPCO began to construct large-scale oil-fired thermal power plants.

Meanwhile, the transmission facilities could not correspond to increases in thermal capacity and short circuit current requirements with the existing $154 \mathrm{kV}$ trunk line system. In addition, a progress in wide area coordinative system operation required closer links with neighbor power companies for sharing reserve capabilities and enhancing electricity exchanges.

Thus, CEPCO introduced a $275 \mathrm{kV}$ system by constructing $275 \mathrm{kV}$ Nagoya Outer Ring System as a trunk line system. The $154 \mathrm{kV}$ system was divided into three systems, with each based respectively on Nishi-Nagoya, Higashi-Nagoya and Electric Power Development Company's (present J-POWER) Nagoya substations on the outer ring system, each balancing demand and 


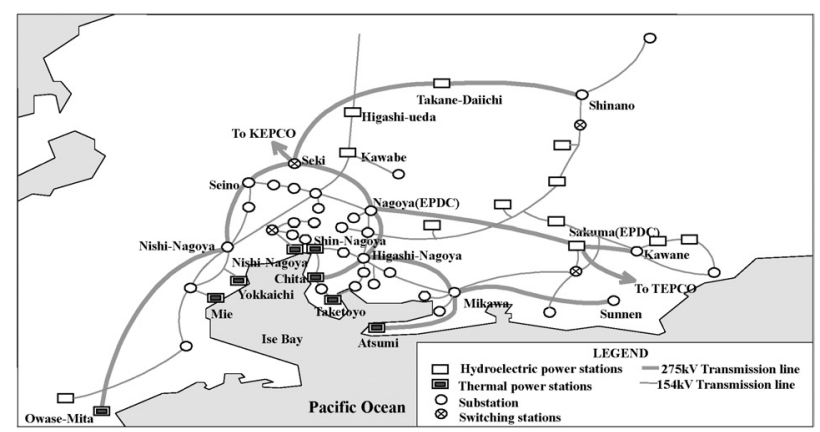

Fig. 2. Power system diagram in 1971

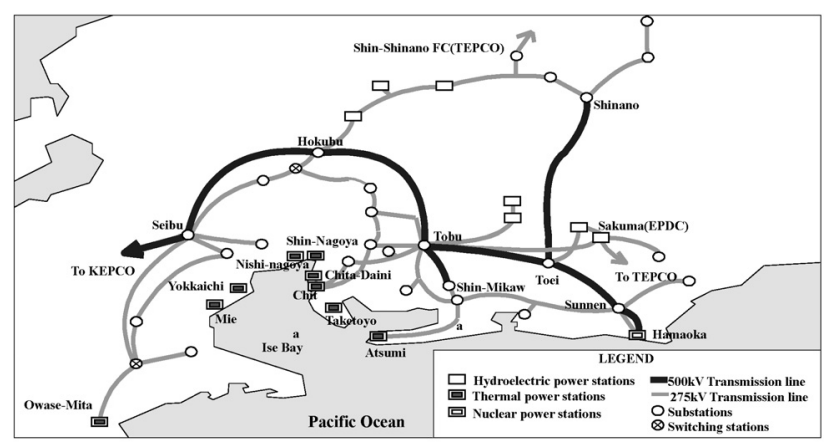

Fig. 3. Power system diagram in 1986

supply independently.

For stable electricity transmission from large-scale oil-fired power plants, $275 \mathrm{kV}$ power source lines were constructed and linked to $275 \mathrm{kV}$ Nagoya Outer Ring System corresponding to power source development. In addition, the $275 \mathrm{kV}$ systems were introduced to major regions for power system and reliability enhancement.

Furthermore, Seki switching station was linked through the $275 \mathrm{kV}$ system to Kansai Electric Power Company in 1960, and a frequency converter (FC) was installed in Electric Power Development Company's Sakuma power plant in 1965, linking CEPCO $(60 \mathrm{~Hz})$ and Tokyo Electric Power Company's power systems $(50 \mathrm{~Hz})$.

2.4 Power System Development up to $\mathbf{1 9 8 6}^{(1)}$ Oil crises in 1973 and 1979 shifted Japanese economy from a rapid growth to a stable growth, reducing electricity demand to an annual average of around $5 \%$.

Accordingly, CEPCO developed its power source with "best mix", which is energy diversification, in mind for energy security. Based on this policy, thermal power source development focused on liquefied natural gas (LNG). In addition, CEPCO made full efforts for nuclear power development as a future alternative to thermal power, commencing operation of long-awaited Hamaoka nuclear power plant in 1976.

Meanwhile, the transmission facilities could not correspond to power system stability and short circuit current requirements from the power source capacity scale-up and remoter location.

Thus, $500 \mathrm{kV}$ systems commenced operation in phases from 1980 to 1986 for transmitting large-scale power sources and linking with Kansai Electric Power Company's power system as well as more stable power supply to Nagano region, securing the stability of entire power system. This made the $275 \mathrm{kV}$ system assume a supplementary role to the $500 \mathrm{kV}$ system of transmitting electricity from power sources located near demand centers and

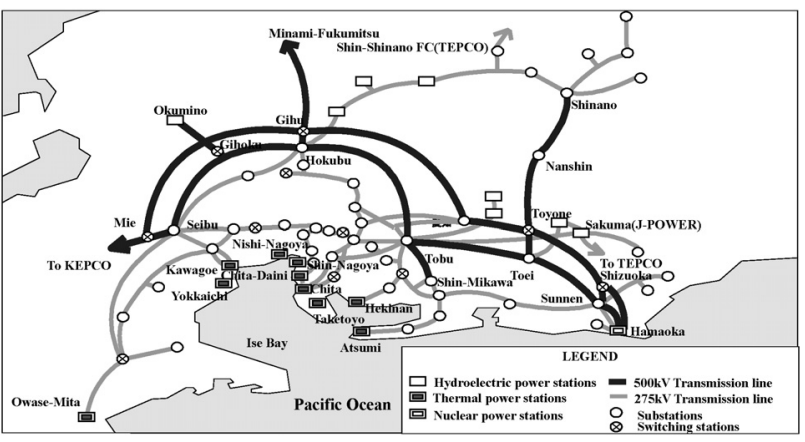

Fig. 4. Power system diagram in 2006

immediate power supply to each region. In addition, a FC was installed at Tokyo Electric Power Company's Shin-Shinano substation for linkage reinforcement with 50Hz systems in 1977 .

\subsection{Power System Development up to the Present (Fiscal} Year End of 2006) ${ }^{(1)} \quad$ Though a bubble economy maintained a high electricity demand growth until 1990, the demand growth has remained generally low since then. Against this background, highly-efficient combined cycle LNG thermal power plants, coal-fired thermal power plants equipped with environment protection technologies and Hamaoka nuclear power plant were constructed according to the basic policy of power source best mix.

Meanwhile, a second $500 \mathrm{kV}$ trunk line system was constructed at the outer circumference of the existing $500 \mathrm{kV}$ trunk line system for securing stable power supply to increasing electricity demand, corresponding to future power system expansion, power source capacity scale-up and remote location as well as preventing any large-scale or long-time outage caused by an unexpected trip of $500 \mathrm{kV}$ trunk lines or key substations, commencing operation in phases from 1993 to 1998 . In addition, three $275 \mathrm{kV}$ underground cable routes from $275 \mathrm{kV}$ key substations at the eastern, southern and western suburbs of Nagoya City to the city center commenced operation in phases from 1988 to 1999, securing stable power supply and enhancing power system reliability.

Furthermore, the FC capacity at Shin-Shinano substation was increased in 1991 for linkage reinforcement with $50 \mathrm{~Hz}$ systems. $500 \mathrm{kV}$ Etsumi trunk line and Minami-Fukumitsu linkage station equipped with Back-To-Back (BTB) converter were also constructed for linking with Hokuriku Electric Power Company's power system.

\section{Progress of Transmission Technologies}

3.1 Transmission Capacity Scale-up The electricity demand increase due to Japanese economic growth as well as power source capacity scale-up and remoter location has brought capacity scale-up and lower inductance to electricity transmission facilities.

The progress of transmission capacity scale-up technologies that CEPCO has adopted shall be described hereafter.

(1) Overhead transmission line capacity scale-up It is said that single copper wire was adopted for the first transmission line in Japan. Later on, with increases in transmission line construction, hard drawn copper (HDC) strand wire that twisted together multiple conductors was adopted for its large capacity and tractability.

Further on, aluminum strand wire that twisted together multiple aluminum conductors, lighter in weight and easier to engineer than 
copper conductors, was adopted for some transmission lines. In succession, aluminum conductor steel reinforced (ACSR) strand wire that twisted multiple aluminum conductors around a zinc galvanized steel core was adopted for some $77 \mathrm{kV}$ transmission lines such as traveled a long span across a river that required high tensile strength. Then, the beginning of earnest domestic production of ACSR made it more advantageous in prices than copper wire, adopted mainly to long span transmission points such as in mountain areas, and becoming the most used material for transmission lines in the post-world-war period.

Configuration of transmission line wire has been shifted to larger number of conductors for corresponding to larger transmission capacity. CEPCO adopted horizontally arranged multiple conductor system for the first time for $77 \mathrm{kV}$ ShinNagoya thermal power plant line in 1958, and four-conductor system of $330 \mathrm{~mm}^{2}$ thermo-resistant aluminum alloy conductor steel reinforced (TACSR) to $275 \mathrm{kV}$ Chita thermal power plant line in 1965. The four-conductor system has been adopted for several transmission lines including Seibu trunk line in the $500 \mathrm{kV}$ outer ring system and $275 \mathrm{kV}$ Tobu-Kitatoyoda line. Furthermore, large bundle radius six-conductor system of $410 \mathrm{~mm}^{2}$ TACSR with $80 \mathrm{~cm}$ conductor spacing was adopted for $275 \mathrm{kV}$ Ise trunk line in 1987 for the first time in the world.

For the second trunk line system, large bundle radius six-conductor system of $810 \mathrm{~mm}^{2}$ TACSR with $80 \mathrm{~cm}$ conductor spacing, the largest among CEPCO's transmission lines, was adopted for transmitting large capacity stably through transmission capacity scale-up and lower inductance. For corresponding to an accompanying scale-up of transmission line towers, high tensile steel and extra-large rolled angle steel were adopted respectively for steel pipe towers and angle steel towers.

Etsumi trunk line, which links Gifu switching station and Minami-Fukumitsu linkage station, is a $500 \mathrm{kV}$ line, spanning $110 \mathrm{~km}$ through steep mountain area that peaks $1,508 \mathrm{~m}$. For corresponding to the harsh weather of high altitude, close geological studies at the planning stage and test results on a full-scale testing line in Nanto City, Toyama Prefecture (then Kami-Taira Village, Higashi-Tonami County) were used to establish the design method of new transmission line.

Extra-large bundle radius six-conductor system of $410 \mathrm{~mm}^{2}$ TACSR, with an extended conductor spacing $(120 \mathrm{~cm})$, was adopted for Etsumi trunk line, for transmission capacity scale-up and lower inductance. For corresponding to an accompanying size-up of line insulators and cost increases, variable bundle radius system, unprecedented across the world, was developed and adopted for some sections of the line.

(2) Underground transmission line capacity scale-up

Underground cable that CEPCO's predecessor company adopted for the first time in 1908 was $11 \mathrm{kV}$ Paper insulated lead sheathed and steel tape armored (PTA) cable for Hagino-Minamibuheicho line $(4.9 \mathrm{~km}, 3 \mathrm{cct})$, which transmitted electricity from hydropower plants in Yaotsu region to Nagoya City. This cable twisted together three phase-cores covered with insulation paper, rolled insulation paper over the outer circumference, coated over with lead, vacuum-dried and impregnated with oil. Figure 6 shows the cable actually used for Hagino-Minamibuheicho line, which was accidentally discovered at a road construction in 2000.

However, PTA cable is not suitable to higher voltage since it has no shielding layer to electrically insulate phases apart. Thus, separately lead sheathed (SL) cable, which had a shielding layer

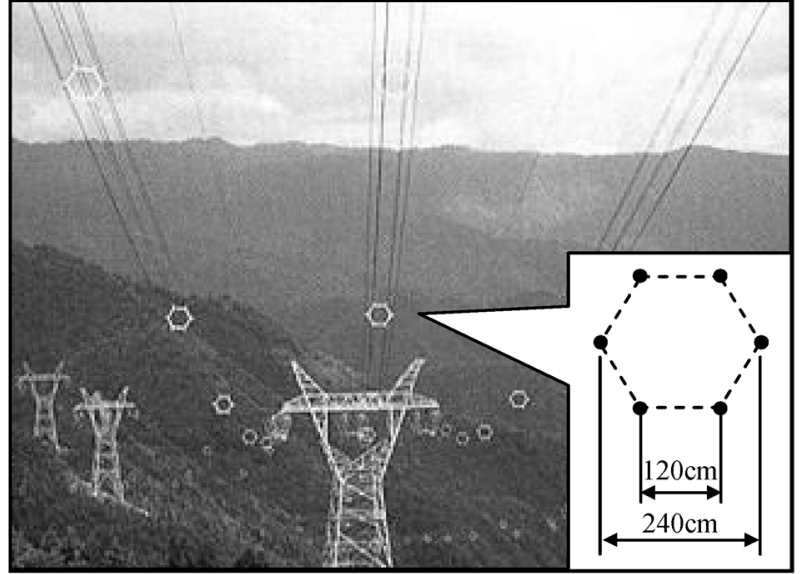

Fig. 5. Extra-large bundle radius six-conductor system of Etsumi trunk line

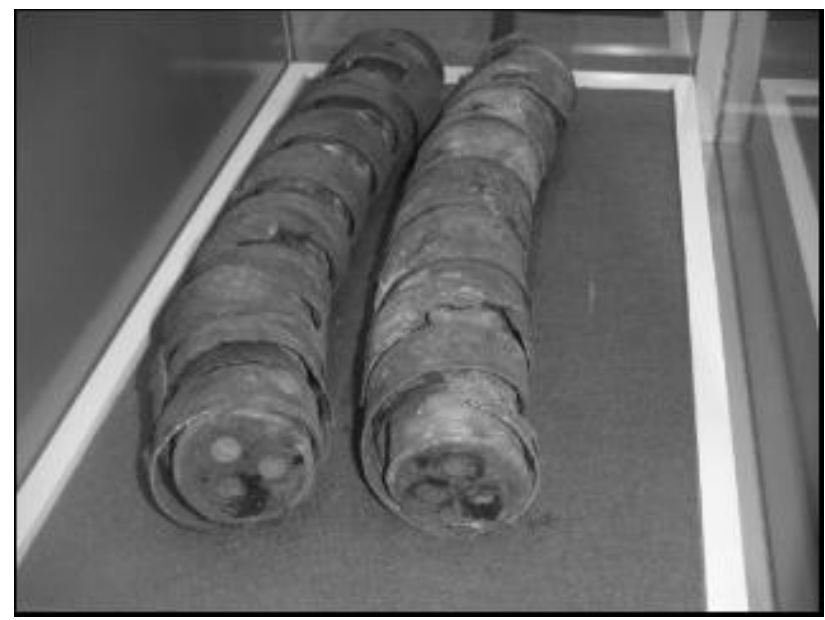

Fig. 6. First underground cable of CEPCO's predecessor company

for each phase-core, allowing higher voltage than PTA cable, was developed. This cable was first adopted for $22 \mathrm{kV}$ Toyoda-Kawabe line in 1937, and then widely used for $33 \mathrm{kV}$ lines bound for Nagoya City region and other lines.

Oil filled (OF) cable, which is press-fed with insulation oil by feeding equipment, allowing higher voltage and larger transmission capacity than oil-impregnated insulation paper cables including PTA and SL cables, was first adopted for a $77 \mathrm{kV}$ customer line, and then $154 \mathrm{kV}$ and $275 \mathrm{kV}$ lines.

For capacity scale-up of OF cable, pipe type oil filled (POF) cable was developed. POF cable, where cooling insulation oil is forced to circulate in steel pipes, allowing transmission capacity scale-up, was adopted for lead-out underground cable of $275 \mathrm{kV}$ Chita-Thermal-Power-Plant linkage line in 1982. This cable employed newly developed $2500 \mathrm{~mm}^{2}$ insulated wire to contain skin effect, realizing a transmission capacity of $830 \mathrm{MW}$, then the world largest.

Currently most used is cross-linked polyethylene insulated vinyl sheathed (CV) cable, which can be used in high temperatures, has less transmission loss and is easy to maintain not requiring any major accessory equipment including oil tanks. CEPCO adopted this cable for the first time for a $22 \mathrm{kV}$ customer line in 1969 , and then continuously improved the cable quality for a wide use from 
distribution line cables to $275 \mathrm{kV}$ underground cables.

These technologies allowed higher voltage and larger transmission capacity, realizing a large transmission capacity, 200 times the early PTA cable (800MW vs. 4MW).

For supplying to Nagoya City, CEPCO has used the above-mentioned large capacity underground cable technologies, the history of which shall be described bellow.

Traditionally, the $154 \mathrm{kV}$ power system supplied Nagoya City center. However, since $154 \mathrm{kV}$ substations had little space for capacity expansion to meet demand increases, and social environment began to require prevention of large-scale or long-time outages, a long-term plan was formulated that Nagoya City center be directly supplied through the $275 \mathrm{kV}$ system from $275 \mathrm{kV}$ substations in the suburb. Based on this plan, three $275 \mathrm{kV}$ underground transmission routes, from east, south and west of Nagoya to the center, were constructed to correspond to demand increases and improve power supply reliability.

As a part of the east route, the first phase of $275 \mathrm{kV}$ system introduction, Umemori-Minamibuheicho line was constructed in 1988. $2,500 \mathrm{~mm}^{2}$ OF cable, the largest conductor size for $275 \mathrm{kV}$ aluminum-covered OF cable, was adopted for this line.

Chita-Daini-Minamibuheicho line (line length: $26.8 \mathrm{~km}$ ), which commenced operation in 1993 as a part of the south route, was the world longest $275 \mathrm{kV} \mathrm{CV}$ cable line then. For underground cables of the south and west routes including the Chita-DainiMinamibuheicho line, $2,500 \mathrm{~mm}^{2}$ stainless-steel-covered CV cable with the world largest capacity was adopted to reduce the transmission loss by $60 \%$ from conventional cables.

Shinmeika-Tohkai line, which commenced operation in 1998 to transmit electricity from Shin-Nagoya thermal power plant, is $275 \mathrm{kV}$ underground gas insulated transmission line (GIL). This GIL is $3.3 \mathrm{~km}$ in line length, the world longest. Three circuits or more of $\mathrm{CV}$ cable are required to transmit the electricity carried by this line, while two circuits of GIL can do the job since GIL can have better heat dissipation than $\mathrm{CV}$ cable by making its conductor surface area larger. After comparing GIL and CV cable multilaterally in terms of lead-out equipment from the substation, cooling equipment, cable compensating reactor (CCR) loss, etc., GIL was chosen for its advantage for a large-capacity transmission line.

\subsection{Progress of Substation Configuration through} Compact-ification Japanese economic growth not only increased electricity demand but also raised land prices and

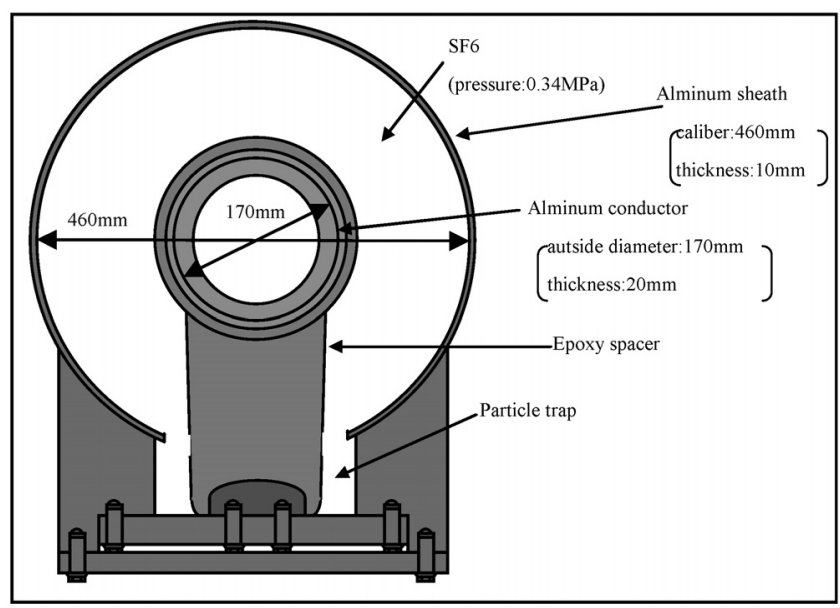

Fig. 7. Structure of GIL generated environmental problems, which gradually raised nationwide awareness of landscape conservation. Understanding of local residents has become harder to obtain for transmission line constructions. Thus, construction sites become harder to obtain, generating constraints on transmission line routes. Even if construction sites are available, they may be too small, thus limitting transmission line construction.

Meanwhile, with the conventional design method, it was obvious that transmission facilities would continue to size up in step with voltage level-up and capacity scale-up. These circumstances required not only transmission line capacity scale-up but also its compactification.

Hereinafter, compactification technologies that CEPCO adopted for its power system facilities and new-types of substation configurations based on the technologies shall be described.

(1) Compactification of substation facilities For substation bus, single-conductor tension bus, copper bar and copper pipe were mostly used at the time of foundation of CEPCO (1951). For the tension bus, copper wires are inserted and soldered in clamp terminals or copper pipes. Currently, aluminum pipe bus is frequently used.

As for bus configuration, double-bus system was adopted for primary substations and extra-high voltage substations, which lead in multiple circuits. However, in this system, the larger number of circuits required the longer bus, thus the larger substation area. Therefore, CEPCO adopted, for the first time in Japan, the double-bus double-side lead-out system as shown in Fig.8, which allowed efficient circuit lead-out on both sides of the bus, reducing the longitudinal bus length. This system was first adopted for Mikawa substation, which commenced operation in 1967, cutting costs drastically through reduction of substation site area. Using this system, the $275 \mathrm{kV}$ field area for a typical $275 \mathrm{kV}$ substation (4cct, 4bank) is reduced by about $15 \%$ from a conventional substation.

However, even with this system, the substation site area reduction had its limitation. Thus, gas insulated switchgear (GIS), which allowed a drastic reduction of substation site area through gas-insulating the entire bus and peripheral equipment, as well as improved the equipment reliability with a future prospect of

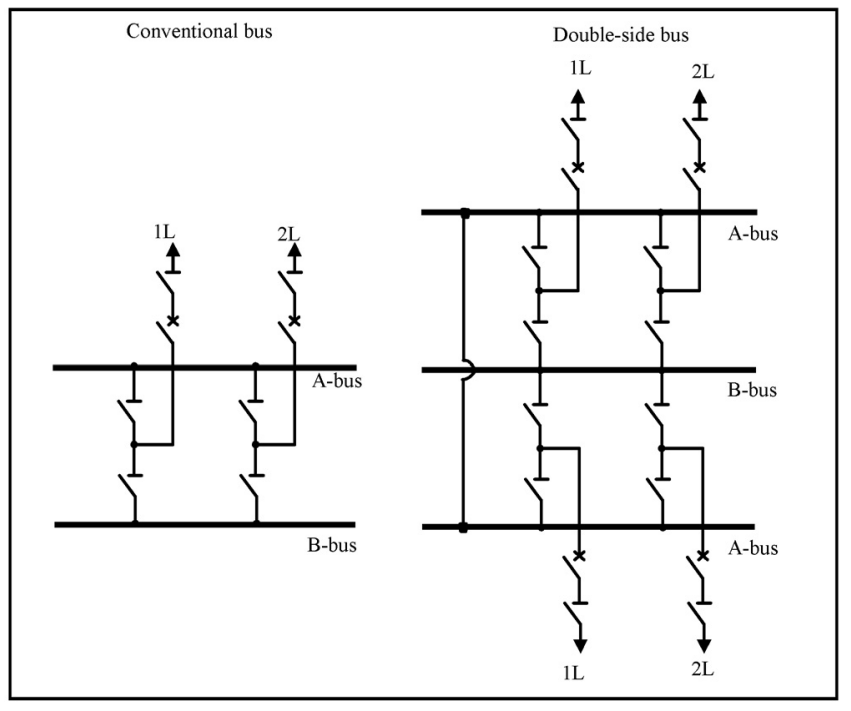

Fig. 8. Comparison between conventional bus system and double-bus double-side lead-out system 


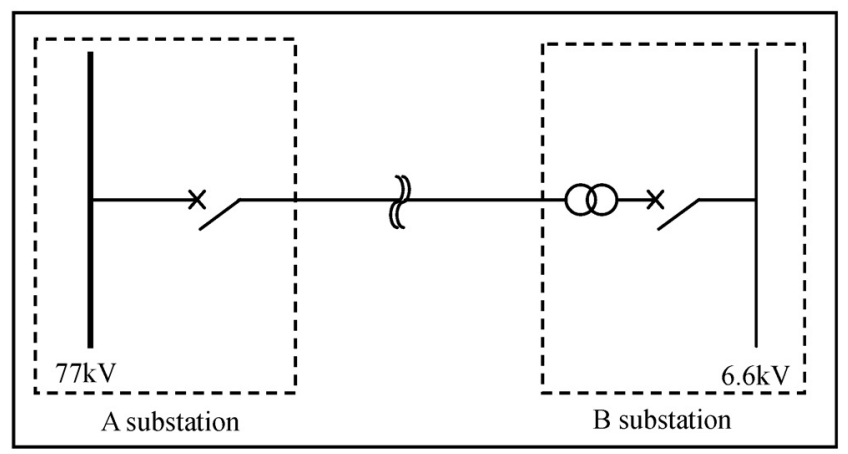

Fig. 9. Unit type lead-in

maintenance-free operation, was developed and adopted.

In 1969, CEPCO's Moriyama substation commenced commercial operation of the first $77 \mathrm{kV}$ GIS in Japan, the oldest among GIS still in operation. This GIS is a phase-separation type, which accommodates its three phase-conductors respectively into separated containers and has served as the basic form for the succeeding GIS development by CEPCO.

$77 \mathrm{kV}$ three-phase packaged type GIS, which accommodates all three phase-conductors into one container, was developed based on the technologies used for phase-separation type GIS for further comactification, and was adopted for the first time at CEPCO for Tokoname substation in 1976. Though the phase-separation type GIS reduced the site area significantly, the three-phase packaged type GIS further reduced the site area by about $60 \%$ from the phase-separation type.

$77 \mathrm{kV}$ compact type GIS was adopted for the first time at CEPCO for Ejiri substation in 1985. This GIS was developed for enhancing equipment reliability and reducing field engineering work period through limiting the docking work to bus conductors for preventing foreign particle invasion. It also reduced the site area further than the three-phase packaged type GIS through standardization of equipment configuration to the basic format of bus-front layout and compactification including adoption of switch-integrated bus, which accommodated disconnecting switches in bus-tanks, and vertical layout of lightning arrestors and instrumental transformers.

GIS also is adopted for $500 \mathrm{kV}$ substations currently. An advanced type of GIS, which realized both compactification and cost reduction through rationalization of insulation and thermal designs that determine the GIS size, was developed for latest $500 \mathrm{kV}$ substations, which CEPCO adopted for Sizuoka substation in 2002 . This GIS reduced site ares to $70 \%$ of conventional types.

In addition, unit type lead-in, which omits the entire primary bus, is adopted for substations in urban area. It omits the primary bus and primary circuit breakers for power transformers by clearing faults on transmission lines through tripping the circuit breaker at the sending end, reducing site area.

(2) Transition of substation configuration With abovementioned compactification technologies, CEPCO began to diversify its substation configuration from the conventional outdoor open-type substation.

CEPCO accommodated the whole $500 \mathrm{kV}$ and $275 \mathrm{kV}$ switchgear at Shin-Mikawa substation that commenced operation in 1983, into GIS, for its first time. Adoption of three-phase packaged main-bus type for $500 \mathrm{kV}$ GIS, the first in the world for this voltage class, reduced site area further than the conventional phase-separation type GIS. These compactification technologies collectively reduced the site area of Shin-Mikawa substation to one third of an open-air substation of the same class.

Meanwhile, urbanization has raised land prices, making it difficult to obtain dedicated sites for substations in city area. In 1960 s, the urbanization rapidly progressed, making land acquisition difficult, especially at around Nagoya railway station and Sakae downtown district. Furthermore, on construction of indoor substations in harmony with their ambient surroundings, administrative limitation on building height and densely packed urban area forced inefficient land usage and economical losses.

Thus, underground substations were constructed under buildings. In urban area (Nagoya City for CEPCO), many transmission and distribution lines had been underground cables, which were easy to lead in to underground substations, providing additional advantage to underground substations.

In 1962, Sasashima substation $(33 \mathrm{kV} / 6.6 \mathrm{kV})$, CEPCO's first underground substation, commenced operation. This substation is unit type that omits the primary circuit breakers for power transformers.

From then on, underground substations advanced to higher voltage levels. In 1993, Matsugae substation, CEPCO's first $275 \mathrm{kV}$ underground substation, commenced operation. This substation was constructed under CEPCO's Chiyoda building, which accommodates its regional and branch offices. Furthermore, in 1999, Meijo substation, the first extra-high voltage substation that CEPCO constructed under a city park, commenced operation. This substation further advanced compactification through adopting not only GIS but also nonflammable power transformers.

\subsection{Progress of Power System Stabilization Technologies}

Complex power system, concentrated and uneven location of power sources required further stabilization and upgrading of operation of the trunk line power system, which advanced power system stabilization tehnologies.

In case of a power system decoupling, System Stabilizing Controller (SSC) sheds required loads or power sources within 0.2 seconds after the decoupling in order to maintain power balance and contain fault spread due to power system turbulence in each decoupled power system. CEPCO installed SSC at HigashiNagoya, Nishi-Nagoya and J-POWER's Nagoya substations in 1968.

Recently, the spread of computer-applied equipment increased automatic load shedding due to voltage drops at power system faults, and the accuracy of power frequency became important even for conventional equipment. CEPCO developed an advanced type SSC and installed it at Tobu substation in 1987, and further improved it continuously into more advanced models. CEPCO also adopted dual system SSC in order to improve its maintenance and operation.

SSC was installed in many parts of CEPCO's power system. However, the construction of $500 \mathrm{kV}$ second trunk line power system made loop operation possible, rendering SSC, which basically adapted to radial power systems, unable to correspond to some situations. Thus, CEPCO developed an advanced type SSC, which corresponds to both loop and radial operations through acquiring information on states of switches at relevant substations and automatically recognizing power system configurations. This advanced SSC is called "concentrated system stabilizing controller (CSC)." Its central processing unit was installed at Aichi substation in 1995, and a new type SSC, which integrated power 


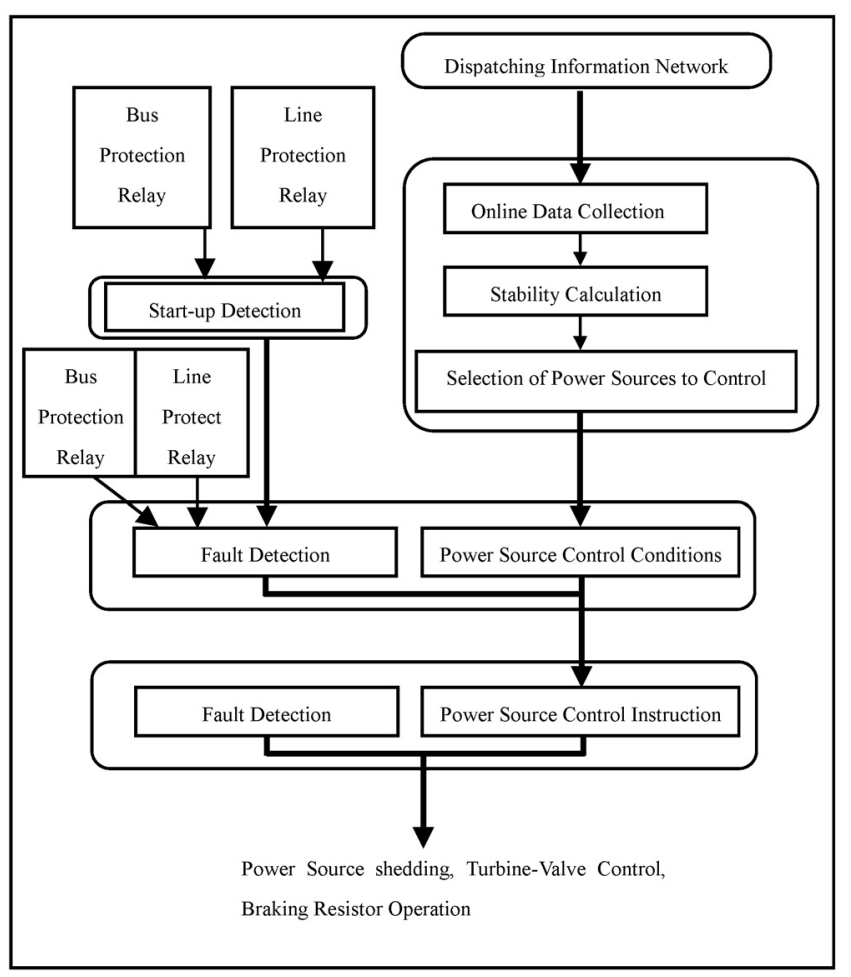

Fig. 10. System configuration of online TSC

plant characteristics into calculation, was adopted for ShinMikawa regional power system in 2000.

While SSC sheds required loads and power sources in order to maintain power balance and contain fault spread due to power system turbulence, transient stability controller (TSC) rapidly trips several generators in order to prevent power system desynchronization in case of transient turbulences of generator internal phase angle due to an abrupt change of power source transmission line impedance, such as in one line fault-trip out of double-circuit transmission lines or fault-trip of looped transmission lines.

TSC includes local TSC and online TSC. CEPCO installed the local TSC at Tobu substation in 1975. However, the construction of $500 \mathrm{kV}$ second trunk line power system, while diversified power system operation was expected, raised concerns that power source operation could not properly correspond to the change of power system configuration, thus constraining its operation. Thus, CEPCO developed online TSC to replace local TSC and put it on commercial operation for the first time in the world. The online TSC collects online information on states of switches (SV information) and measurements (TM information) of line currents, bus voltages, generator outputs and others from power dispatching information network and calculates power system stability based on the collected information, thus selecting the most suitable generators to control at the moment. CEPCO introduced TSC to the trunk line power system in 1995, and then extended its application to power plant transmission lines in phases.

Main characteristics of online TSC are described bellow.

(i ) Online TSC automatically recognizes changes in state of power system and connected generators, selecting generators to control for power system stabilization.

(ii ) Online TSC calculates power system stability based on $\mathrm{SV}$ and TM information on the online power system at several minutes interval, thus allowing power system stabilization with a minimum required power source control.

(iii) Online TSC corresponds to generator addition and power system expansion through data renewal, not requiring any equipment refurbishment.

\section{Future Challenges and Prospects for Power System Planning}

The progress of power transmission technologies was above described. The transmission capacity scale-up and lower inductance that the progress brought are creating new problems including increases in short circuit and ground fault currents, which requires multilateral solutions. Meanwhile, increasingly complex power system and customer needs require further improvement in power system reliability and stability technologies.

Furthermore, two major changes in business environment, which are electricity market liberalization and rising public awareness of environment and right consciousness, may bring new challenges on power system planning.

Hereafter shall be described technologies required for future power system planning and expected challenges.

\subsection{Further Progress of Technologies Required}

Recently, the spread of high-pressure discharge lamps and precision equipment including computers increased the number of customers affected by instantaneous voltage drops. Especially, factories that use power electronics equipment sensitive to voltage drops suffer large influence including production-line suspension and products damage, raising concerns of electricity customers. In addition, further spread of distributed power sources may increase power frequency fluctuation and generate harmonics, affecting neighbor customers.

Though CEPCO has implemented countermeasures to prevent power quality deterioration including installation of lightning arrestors on transmission lines and selection of most suitable series-reactors, customers' needs for high quality power supply are still ever rising. In the future, further progress of reliability technologies is required for corresponding to those needs and implementing inexpensive countermeasures.

Meanwhile, difficulties in land acquisition for power sources will make power source sites remoter. Static compensator (STATCOM) and superconducting magnetic energy storage (SMES) are considered as countermeasures for stabilizing long-distance large-capacity transmission lines from these remote power sources. These new technologies for power system stability shall be required for optimum power system planning in the future.

\subsection{Cross-Sectoral Solutions (System Coordination)} Required $^{(1)} \quad$ Recent changes in power facility and system characteristics, including capacity scale-up due to concentrated and remote power source site and lower inductance of transmission lines due to multiple conductor system, expanded power system and raised short circuit currents and DC current damping time constant. Increase of large-scale power producer and suppliers (PPS) due to electricity market liberalization and spread of distributed power sources may also change power system characteristics drastically.

While power source and transmission sectors traditionally had cooperated in corresponding to these problems, consensus in the liberalized electricity market is that the transmission sector should be responsible. However, multilateral solutions from all 
stakeholders including transmission, power source, customers and equipment manufactures are more reasonable for these complex technology problems. For example, a large short circuit current in a local power system that a new power source is to be linked can be reasonably coped with through adopting the most suitable generator equipment. Other examples include harmonics and midnight voltage-rise that can be attributed to particular customers and difficult to solve without cooperation of those customers. Cross-sectoral system coordination not only from transmission sector but also from power producers, customers and equipment manufactures is required to optimize transmission facilities in a multilateral perspective.

\subsection{Difficulties in Transmission Facility Construction due} to Rising Public Awareness of Environment and Right Consciousness $^{(1)} \quad$ Rising public awareness of environment and right consciousness, such as landscape conservation, electromagnetic field, rare plant and animal protection, are making difficult delaying acquisition of understanding of local governments and residents toward transmission facility construction, as well as bringing uncertainties of construction schedule. The lead-time from power source development to transmission line construction will grow and in some cases transmission construction may lag behind power source development.

Further efforts including landscape-friendly facilities including aesthetic line towers, educational activities for understanding electromagnetic field, construction schedule with consideration for nesting seasons, etc. are required for transmission facilities to be accepted in local communities.

\section{Summary}

This paper reviewed CEPCO's history of power system formation and progress in transmission technologies, and describes future challenges.

Difficulties in land acquisition and complexity in power system will grow in the future. Further progress of transmission technologies is required for optimum power system planning best suited to difficult land acquisition and complex power system configuration.

Uncertainties of power source planning are also making reasonable transmission planning difficult. Sufficient consideration and evaluation on effects that changes in business situation bring are required for optimum power system planning from a multilateral perspective on the entire power system.

(Manuscript received April 19, 2007, revised Sept. 18, 2007)

\section{References}

(1) Y. Johgo and Y. Sudo : "Past Expansion and Future Prospects of the Power System in Chubu Electric Power Company", 2005 National Convention Record IEE Japan, Vol.6, pp.6S7(13)-6S7(16) (2005)

Hirotaka Takagi (Member) was born in Aichi, Japan, on November

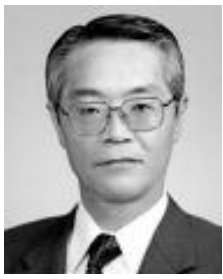
13,1950. He received a master's degree in electrical engineering from Nagoya University in 1976, and is presently head of Electrical engineering department at Chubu Electric Power CO. He served vice president of IEEJ.

Tomonari Sugiyama

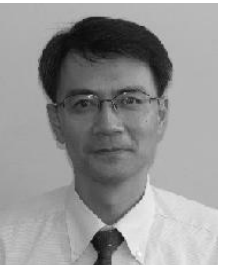

Toshihito Zashibo

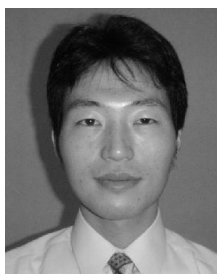

(Member) was born in Aichi, Japan, on November 27, 1959. He received a master's degree in electrical engineering from Kyoto University in 1984, and is presently head of Planning section of Electrical engineering department at Chubu Electric Power CO. He has worked on planning power system.

(Member) was born in Toyama, Japan, on October 27, 1976. He received a master's degree in electrical engineering from Niigata University in 2001, and is presently an engineer at Chubu Electric Power CO. He has worked on planning power system. 